Benjamin Constant

Euvres complètes

\title{
Euvres
}

XIV 


\title{
Benjamin Constant CEuvres complètes Série Euvres XIV
}

\author{
Comité directeur \\ Président: Paul Delbouille \\ Jean-Daniel Candaux, C. P. Courtney, Pierre Deguise, Brian Juden, \\ Norman King, Kurt Kloocke, Claude Reymond, Patrice Thompson
}

\section{Conseil scientifique}

Président: Claude Reymond - Secrétaire: Étienne Hofmann Simone Balayé, Jean-Charles Biaudet, $\uparrow$ Pierre Cordey, Maurice Déchery, Michel Delon, Alison Fairlie, Françoise Fornerod, Doris Jakubec, Béatrice Jasinski, François Jequier, Mario Matucci, Roland Mortier, Lucia Omacini, †Victor de Pange, Corrado Rosso, Martine de Rougemont, Lionello Sozzi, Arnaud Tripet, Norbert Waszek, Markus Winkler, Dennis Wood ainsi que les membres du Comité directeur

Ce volume appartient à la troisième période (1813-1821) dirigée par Kurt Kloocke

La révision en a été assurée par Jean-Charles Biaudet 


\section{Benjamin Constant}

\section{Mémoires sur les Cent-Jours}

Volume dirigé et texte établi par

Kurt Kloocke

Introduction et notes par

André Cabanis

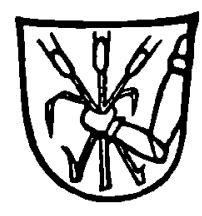

Max Niemeyer Verlag

Tübingen 1993 
Die Deutsche Bibliothek - CIP-Einheitsaufnahme

Constant, Benjamin:

Oeuvres complètes / Benjamin Constant. - Tübingen : Niemeyer. Sér. 1, Oeuvres.

NE: Constant, Benjamin: [Sammlung]

14. Mémoires sur les cent-jours / vol. dirigé et texte établi par Kurt Kloocke. Introd. et notes par André Cabanis. - 1993

NE: Kloocke, Kurt [Hrsg.]

ISBN 3-484-50414-5

(c) Max Niemeyer Verlag GmbH \& Co. KG, Tübingen 1993

Das Werk einschließlich aller seiner Teile ist urheberrechtlich geschützt. Jede Verwertung außerhalb der engen Grenzen des Urheberrechtsgesetzes ist ohne Zustimmung des Verlages unzulässig und strafbar. Das gilt insbesondere für Vervielfältigungen, Übersetzungen, Mikroverfilmungen und die Einspeicherung und Verarbeitung in elektronischen Systemen.

Printed in Germany.

Satz: pagina $\mathrm{GmbH}$, Tübingen

Druck: Allgäuer Zeitungsverlag, Kempten

Einband: Heinr. Koch, Tübingen 